\title{
New waterborne polyurethane-based nanocomposites reinforced with low loading levels of chitin whisker
}

\author{
J. Huang ${ }^{1,3,5}$, J. W. Zou', P. R. Chang ${ }^{2 *}$, J. H. Yu ${ }^{3}$, A. Dufresne ${ }^{4}$ \\ ${ }^{1}$ College of Chemical Engineering, Wuhan University of Technology, Wuhan 430070, P.R. China \\ ${ }^{2}$ Bioproducts and Bioprocesses National Science Program, Agriculture and Agri-Food Canada, 107 Science Place, \\ Saskatoon, SK, S7N 0X2, Canada \\ ${ }^{3}$ Interdisciplinary Science and Technology Institute for Advanced Study, East China Normal University, Shanghai \\ 200062, P.R. China \\ ${ }^{4}$ The International School of Paper, Print Media and Biomaterials (Pagora), Grenoble Institute of Technology, \\ BP 65 - 38402 Saint Martin d'Hères Cedex, France \\ ${ }^{5}$ State Key Laboratory of Pulp and Paper Engineering, South China University of Technology, Guangzhou 510640, P.R. \\ China
}

Received 2 September 2010; accepted in revised form 17 November 2010

\begin{abstract}
New waterborne polyurethane (WPU)-based nanocomposites were prepared by incorporating low loading levels of chitin whiskers (ChWs) as the nanophase. The resultant WPU/ChW nanocomposites exhibited prominent enhancement in both strength and Young's modulus, and maintained an elongation of greater than ca. $500 \%$. The ChW loading level of $3 \mathrm{wt} \%$ showed the maximum tensile strength (28.8 MPa) and enhanced Young's modulus (6.5 MPa), ca.1.8- and 2.2-fold over those of neat WPU. The active surface and rigidity of $\mathrm{ChW}$ facilitated formation of the interface for stress transferring and contributed to higher stress-endurance. As the ChW loading level increased, self-aggregation of ChWs resulted in a decrease in strength; however, the rigidity of $\mathrm{ChW}$ still supported the increase in Young's modulus, and the nanocomposites containing $5 \mathrm{wt} \% \mathrm{ChWs}$ had the highest Young's modulus $(9.6 \mathrm{MPa})$. This work enriches the research into achieving high mechanical performance of waterborne polyurethane-based nanocomposites by introducing a natural nanofiller, and this high performance 'green' bionanocomposites will likely have promising prospects.
\end{abstract}

Keywords: nanocomposites, waterborne polyurethane, chitin whisker

\section{Introduction}

Public concern over the environment, the depletion of fossil fuels, and climate change has promoted the development of bionanocomposites in the past decade. Compared to polymeric resources from petroleum, natural polymers from renewable resources have the advantages of biodegradability, biocompatibility, non-toxicity, high reactivity, low cost, ease of availability, and so forth [1-3]. Natural nanofillers are the crystalline residues after acidic or alkaline hydrolysis of natural polysaccharides, most notably the rod-like whiskers of cellulose [4] and chitin [5], and the platelet-like nanocrystal of starch $[6,7]$. These nanofillers not only inherit all the advantages of the natural polymers, but also have a reinforcing function in composites, similar to traditional inorganic nanofillers [4, 5, 8-10], by virtue of their rigidity. Moreover, compared with inorganic nanofillers, the relatively active surface of natural nanofillers makes it easy to perform chemical derivation and grafting [11-13] or to form strong physical interactions.

\footnotetext{
${ }^{*}$ Corresponding author, e-mail: peter.chang@agr.gc.ca
}

(c) BME-PT 
Chitin, a natural polymer, is an abundant renewable resource [14]. Structurally, chitin is very similar to cellulose, except that its basic monosaccharide is 2-acetamido-2-deoxy-D-glucose ( $N$-acetyl-D-glucosamine). Chitin and its derivatives have excellent biocompatibility and physiological non-toxicity, such that it may be used for drug delivery, cell culture anticoagulant, sutures and coagulant, etc. [1517]. Chitin whiskers (ChWs), obtained by removing protein and other impurities from chitin, also possess excellent rigidity and intensity and are often used as a reinforcing agent in nanocomposites [18]. They are being widely used in aerospace flight vehicle elements and components, as well as in the chemical industry, machinery, motorcars, biomedicine and other industrial applications. Nair and Dufresne [19] reported significant improvement in the mechanical properties of natural rubber reinforced by ChWs. Lu et al. [20] incorporated ChWs into soy protein to prepare thermoplastic composites, further confirming the reinforcing role $\mathrm{ChW}$ nanofillers play in composites.

Due to increasing concerns about human health and environmental-friendliness, organic, solvent-free polyurethane (i.e. waterborne polyurethane, WPU) with its low volatile organic compound (VOC) levels and non-toxicity has been rapidly developed and applied [21, 22]. Environmentally-friendly WPU can be applied to leather and textile finishing, floor coverings, adhesives, pressure sensitive adhesives, and so on [23-27]. Starch [28], soy protein [29], lignin [30], and chitin derivative [31] have been incorporated into WPU for the purposes of reducing cost, improving biodegradability, and enhancing mechanical performance. Additionally, cellulose whisker has also been filled into a WPU matrix as a reinforcing nanophase, resulting in a significant increase in strength and Young's modulus [32].

In this work, we incorporated very low loading levels of ChWs into WPU to prepare WPU/ChW nanocomposites. Subsequently, the structure and mechanical properties of the resultant nanocomposite materials were investigated by attenuated total reflection-Fourier transform infrared spectroscopy (ATR-FTIR), X-ray diffraction (XRD), differential scanning calorimetry (DSC), dynamic mechanical analysis (DMA), scanning electron microscopy (SEM) and tensile tests.

\section{Experimental part}

\subsection{Materials}

Chitin (crab shell) was purchased from Yuhuan Ocean Biochemical Co. Ltd. (Zhejiang, China), and used as received. Polycaprolactone, with a numberaverage molecular weight $\left(M_{\mathrm{n}}\right)$ of $2000\left(\mathrm{PCL}_{2000}\right)$, was purchased from Sigma-Aldrich Chemical Co. (Saint Louis, MO, USA). Diphenyl-methane-diisocyanate (MDI-100) was purchased from Yantai Wanhua Polyurethanes Co. Ltd. (Shandong, China). Dimethylol propionic acid (DMPA) was donated by Huzhou Changsheng Chemical Co. Ltd. (Zhejiang, China), and dehydrated under vacuum at $60^{\circ} \mathrm{C}$ for $12 \mathrm{~h}$. Triethylamine (TEA) was purchased from Sinopharm Chemical Reagent Co. Ltd. (Shanghai, China), and redistilled before use. Analytical grade butanone solvent was purchased from Sinopharm Chemical Reagent Co. Ltd. (Shanghai, China) and dehydrated by adding $\mathrm{CaH}_{2}$ and then distilling.

\subsection{Preparation of chitin whiskers}

According to the previous report [19], the procedure used for preparing a stable suspension of chitin whiskers is described as follows: Chitin was first boiled and mechanically stirred in a $5 \% \mathrm{KOH}$ solution for $6 \mathrm{~h}$ to remove most of the proteins. It was then kept at room temperature overnight under constant stirring, followed by filtering and washing several times with distilled water. The resultant solid was bleached with $17 \mathrm{~g}$ of $\mathrm{NaClO}_{2}$ in $110.3 \mathrm{M}$ $\mathrm{CH}_{3} \mathrm{COONa}$ for $6 \mathrm{~h}$ at $80^{\circ} \mathrm{C}$, and the bleach solution changed every $2 \mathrm{~h}$. After bleaching, the suspension was kept in a $5 \% \mathrm{KOH}$ solution for $48 \mathrm{~h}$ to remove residual proteins and then centrifuged at $3600 \mathrm{rpm}$ for $15 \mathrm{~min}$. The purified chitin was hydrolyzed with boiling $3 \mathrm{~N} \mathrm{HCl}$ for 90 min under mechanical stirring $(30 \mathrm{ml} \mathrm{HCl}$ per $1 \mathrm{~g}$ chitin). Finally, the acid hydrolyzed suspension was diluted with distilled water, centrifuged (36000 rpm for $15 \mathrm{~min}$ ), and then dialyzed until the $\mathrm{pH}$ reached 4.0. The resultant chitin whiskers were completely dispersed using ultrasonic treatment or vigorous mechanical shearing, and stored at $6^{\circ} \mathrm{C}$ after adding sodium azide to inhibit bacterial growth.

\subsection{Preparation of WPU/ChW nanocomposites}

The synthesis of waterborne polyurethane (WPU) is depicted as follows: Both $4.98 \mathrm{~g} \mathrm{PCL}_{2000}$ and $2.23 \mathrm{~g}$ 
MDI were first dissolved in $10 \mathrm{~g}$ butanone and then placed into a three-necked round-bottomed flask equipped with a mechanical stirrer, a reflux condenser, and a dry nitrogen inlet. The reactant was then heated to ca. $70^{\circ} \mathrm{C}$, and kept under a nitrogen atmosphere for $2 \mathrm{~h}$ with mechanical stirring. Thereafter, $0.46 \mathrm{~g}$ DMPA, a chain-extender, was dispersed in butanone and added to give a $\mathrm{NCO} / \mathrm{OH}$ molar ratio of 1.6. The reaction temperature was elevated to $85^{\circ} \mathrm{C}$ and held here for $1 \mathrm{~h}$. During this period butanone was occasionally added in order to lower the viscidity of the reactant. Afterward, the resultant product was cooled to less than $40^{\circ} \mathrm{C}$, and then the $-\mathrm{COOH}$ of DMPA in the polyurethane chains was neutralized by adding $0.34 \mathrm{~g}$ TEA. Emulsification was subsequently carried out by adding icy water under severe shear to produce WPU latex with a solids content of $20 \mathrm{wt} \%$. Finally, the desired amount of ChWs suspended in distilled water was added and the reaction was allowed to continue for another $0.5 \mathrm{~h}$. The WPU latex was cast onto a Teflon mold after vacuum degassing, and allowed to solidify as a film at $60^{\circ} \mathrm{C}$ via water evaporation. By changing the ChWs content over a range of $0,1,2,3,4$, and $5 \mathrm{wt} \%$, a series of nanocomposite films were obtained, and coded as WPU, WPU/ChW-1, WPU/ChW-2, WPU/ChW-3, WPU/ ChW-4 and WPU/ChW-5, respectively. The resultant films were stored at room temperature in a desiccator containing $\mathrm{P}_{2} \mathrm{O}_{5}$ with $0 \%$ relative humidity (RH) for 5 days.

\subsection{Characterization}

\subsubsection{FTIR analysis}

Attenuated total reflectance-Fourier transform infrared (ATR-FTIR) spectra of all the films were recorded on a FTIR 5700 spectrometer (Nicolet, USA). The films were scanned in the range of 4000 $700 \mathrm{~cm}^{-1}$ using Smart OMNT reflect accessories.

\subsubsection{X-ray diffraction (XRD)}

$\mathrm{X}$-ray diffraction measurements were performed on a D/max-IIIA X-ray diffractometer (Rigaku Denki, Tokyo, Japan) using $\mathrm{Cu} \mathrm{K}_{\alpha}$ radiation $(\lambda=0.154 \mathrm{~nm})$ at $40 \mathrm{kV}$ and $60 \mathrm{~mA}$ with a scan rate of $12^{\circ} \cdot \mathrm{min}^{-1}$. The diffraction angle of $2 \theta$ ranged from 2 to $60^{\circ}$.

\subsubsection{Atomic force microscopy (AFM)}

Atomic force microscopy was performed on a Digital 3100 IIIa microscope (USA). A droplet of a dilute whisker suspension was coated onto a flake of mica, and the water was evaporated at room temperature.

\subsubsection{Scanning electron microscope (SEM)}

Scanning electron microscope observation was carried out on an S-4800 scanning electron microscope (Hitachi, Japan) with an accelerating voltage of $10 \mathrm{kV}$. The films were frozen in liquid nitrogen and then snapped immediately. The fracture surfaces were sputtered with Pt, and then observed and photographed.

\subsubsection{Differential scanning calorimetry (DSC)}

Differential scanning calorimetry analysis was carried out on a DSC-204 instrument (Netzsch, Germany) under a nitrogen atmosphere at a heating or cooling rate of $20^{\circ} \mathrm{C} \cdot \mathrm{min}^{-1}$. The specimen was scanned over the range of -150 to $100^{\circ} \mathrm{C}$ after a pretreatment to eliminate thermal history and remove volatiles (heating from 20 to $100^{\circ} \mathrm{C}$ and then cooling to $\left.-150^{\circ} \mathrm{C}\right)$.

\subsubsection{Dynamic mechanical analysis (DMA)}

Dynamic mechanical analysis measurement was carried out on a DMA-242C dynamic mechanical analyzer (Netzsch, Germany) at a frequency of $1 \mathrm{~Hz}$ over the range of -150 to $100 \mathrm{C}$ with a heating rate of $3^{\circ} \mathrm{C} \cdot \mathrm{min}^{-1}$. A dual cantilever device was used and the specimen size was $40 \times 10 \times$ ca. $0.5 \mathrm{~mm}^{3}$.

\subsubsection{Tensile test}

The tensile strength $\left(\sigma_{\mathrm{b}}\right)$, elongation at break $\left(\varepsilon_{\mathrm{b}}\right)$ and Young's modulus $(E)$ were measured on a CMT6503 universal testing machine (SANS, Shenzhen, China) with a crosshead rate of $100 \mathrm{~mm} \cdot \mathrm{min}^{-1}$ according to method GB13022-91. The tested specimens were cut into quadrate strips $10 \mathrm{~mm}$ wide and the distance between testing marks was $30 \mathrm{~mm}$. The average value of five replicates of each sample was taken.

\section{Results and discussion 3.1. Chitin whiskers}

The AFM image of a dilute suspension of chitin whiskers (ChWs) is shown in Figure 1. The suspen- 


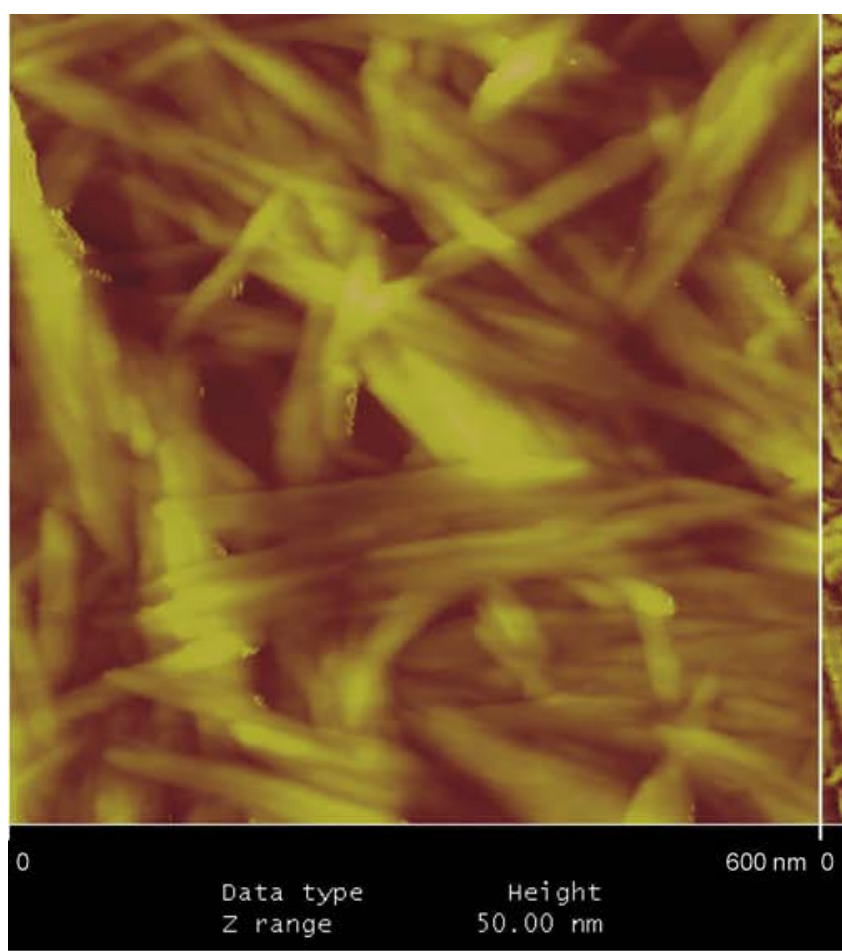

a)

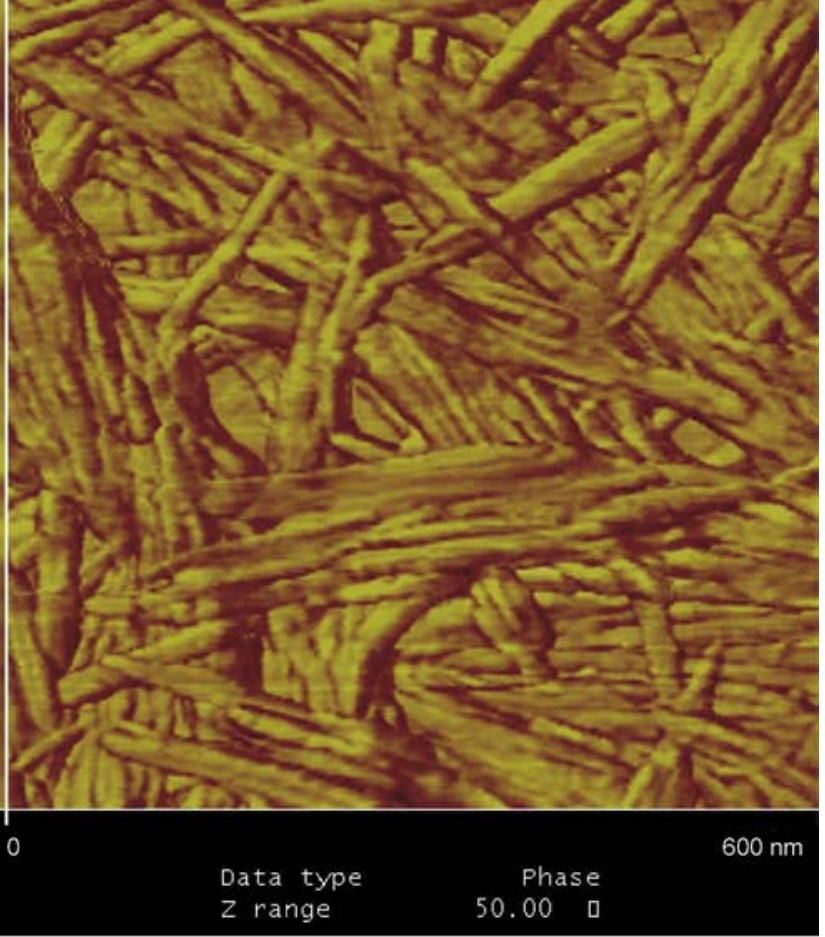

b)

Figure 1. AFM images of a dilute suspension of chitin whiskers (a) height image; b) phase image)

sion consisted of individual chitin fragments having a spindle shape. These fragments had a broad distribution in length $(L)$, ranging from 100 to $350 \mathrm{~nm}$, and diameter $(D)$, ranging from 5 to $35 \mathrm{~nm}$. Exact determination of the latter was difficult because of both the tapering of the chitin fragments and the presence of narrow microcrystals. The average of length and diameter were estimated to be $250 \pm 50$ and $20 \pm 10 \mathrm{~nm}$, respectively; therefore, the average aspect ratio, i.e. $L / D$, was $12.5 \pm 5$, which is very close to the dimensions of squid pen $(L=50 \sim 300 \mathrm{~nm}$, $D=10 \mathrm{~nm}, L / D=15$ ) [5] but much lower than chitin from Riftia tubers $(L=0.5 \sim 10 \mu \mathrm{m}, D=18 \mathrm{~nm}$, $L / D=120$ ) [33]. For a three-dimensional network, the critical volume fraction $\left(V_{\mathrm{Rc}}\right)$ depends on the aspect ratio $(L / D=12.5)$ of the chitin whiskers since $V_{\mathrm{Rc}}=0.7(L / D)$ [19]. Substitution of the $L / D$ value of chitin whiskers into that equation yields a value of $V_{\mathrm{Rc}}=5.6 \mathrm{vol} \%$, or ca. $8.4 \mathrm{wt} \%$. The highest ChWs content in this work was $5 \mathrm{wt} \%$, which is lower than the critical weight fraction, so a threedimensional network of chitin whiskers was absent in the as-prepared nanocomposites.

\subsection{Mechanical properties of nanocomposites}

Figure 2 shows the effects of the $\mathrm{ChW}$ loading level on the mechanical properties of the WPU/ChW

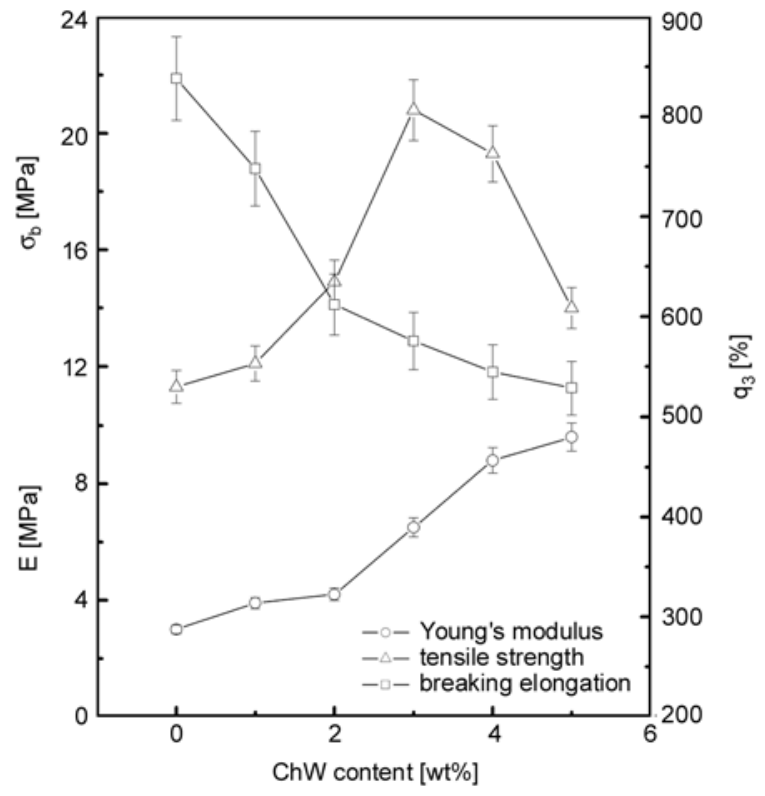

Figure 2. Effects of ChW loading level on tensile strength $\left(\sigma_{\mathrm{b}}\right)$, elongation at break $\left(\varepsilon_{\mathrm{b}}\right)$ and Young's modulus $(E)$ of WPU/ChW nanocomposite films, with WPU film as reference

nanocomposites, including tensile strength $\left(\sigma_{\mathrm{b}}\right)$, Young's modulus $(E)$ and elongation at break $\left(\varepsilon_{\mathrm{b}}\right)$. As expected, the rigidity of $\mathrm{ChW}$ enhanced the strength of WPU significantly. Compared with $\sigma_{\mathrm{b}}$ of $11.3 \mathrm{MPa}$ and $E$ of $3.0 \mathrm{MPa}$ for neat WPU, the $\sigma_{\mathrm{b}}$ and $E$ values of the WPU/ChW nanocomposites 
were both enhanced. When the ChW loading level was $3 \mathrm{wt} \%, \sigma_{\mathrm{b}}$ reached a maximum value of $20.8 \mathrm{MPa}$, approximately 1.8 -fold over that of neat WPU. Thereafter, the continuous increase in the ChW loading level resulted in a slight decrease in $\sigma \mathrm{b}$, but the value of $E$ continued to increase. When the $\mathrm{ChW}$ loading level reached $5 \mathrm{wt} \%, E$ increased to $9.6 \mathrm{MPa}$, ca. 3.2-fold over that of neat WPU. On the other hand, the change in $\varepsilon_{\mathrm{b}}$ as the ChWs content increased was just opposite of $E$, and all the $\varepsilon_{\mathrm{b}}$ values of the WPU/ChW nanocomposites were lower than that of neat WPU. In other words, enhancement of the strength and Young's modulus occurred at the expense of elongation; however, compared with the obvious enhancement of $\sigma_{\mathrm{b}}$ and $E$, a certain level of decline in $\varepsilon_{\mathrm{b}}$ is acceptable. From the above results, we found that neat ChWs had an evident reinforcing role, furthermore, with a $\mathrm{ChW}$ content of $3 \mathrm{wt} \%, \sigma_{\mathrm{b}}$ reached the maximum value and $E$ reached $6.5 \mathrm{MPa}$, which were ca. 1.8 and 2.2fold over those of neat WPU, respectively. At this time, the $\varepsilon_{\mathrm{b}}$ value of the nanocomposites remained at $575.4 \%$. Enhancement of the nanocomposite mechanical properties by ChWs may be attributed to the uniform dispersion of ChWs at the nanoscale as well as to the physical interaction between the ChW nanofiller and the WPU matrix [34] for the transfer of stress to the rigid $\mathrm{ChW}$ nanofiller. However, with an increase in the loading level of ChWs, self-aggregation of ChWs may break the original structure and interaction in the WPU matrix, resulting in a decrease in strength and elongation. The rigid nature of $\mathrm{ChW}$ and its aggregate, however, maintained the continuous increase in Young modulus.

\subsection{Hydrogen bonding in nanocomposites}

ATR-FTIR spectra of the WPU/ChW nanocomposites and the neat WPU are shown in Figure 3a. As is well known, the hydrogen bond is an essential physical interaction in waterborne polyurethane affecting the microphase separation structure and mechanical properties of materials [35]. In this case, the $-\mathrm{NH}$ in the hard-segment was hydrogenbonded with the $-\mathrm{C}=\mathrm{O}$ of the hard-segments, the ester $-\mathrm{C}=\mathrm{O}$ of the $\mathrm{PCL}_{2000}$ soft-segments and the $-\mathrm{C}=\mathrm{O}$ on the $\mathrm{ChW}$ surface. In addition, $-\mathrm{OH}$ on the $\mathrm{ChW}$ surface also participated in hydrogen bonding with the $-\mathrm{C}=\mathrm{O}$ in the soft- and hard- segments. All the nanocomposites showed the analogical $-\mathrm{NH}$ bands with the main peak located at ca. $3314 \mathrm{~cm}^{-1}$ despite the absorption of $-\mathrm{OH}$ in ChWs being embedded in them. As a result, absorptions in the range of $3450 \sim 3250 \mathrm{~cm}^{-1}$ for all the WPU/ChW nanocomposites and WPU were divided into two peaks by curve-fitting (Figure 3b), i.e. Peak I located at $3391-3394 \mathrm{~cm}^{-1}$ and Peak II located at $3320-3339 \mathrm{~cm}^{-1}$. The former was the free $-\mathrm{NH}$ absorption while the latter was the absorption of hydrogen-bonded -NH for WPU, or included the additional $-\mathrm{OH}$ absorption for the WPU/ChW nanocomposites. Table 1 summarizes the detailed locations and fractions of Peaks I and II for all the WPU/ChW nanocomposites and for WPU. The increasing Peak II fraction was not proportional to the increment contributed by $-\mathrm{OH}$ absorption, indicating that the original hydrogen bonds associated with $-\mathrm{NH}$ in the WPU matrix cleaved. When the ChW loading level was lower than $2 \mathrm{wt} \%$, the relatively prominent increase in the fraction for Peak II was attributed to less inhibition to the original -NH-based hydrogen bonding, and to the formation of hydrogen bonds associated with $-\mathrm{OH},-\mathrm{NH}-$ and $-\mathrm{C}=\mathrm{O}$ on the $\mathrm{ChW}$ surface. The analogical $-\mathrm{C}=\mathrm{O}$ bands of the WPU/ChW nanocomposites and WPU were also divided into three peaks (Figure 3c), namely Peak III from the free $-\mathrm{C}=\mathrm{O}$ located at $1730-1732 \mathrm{~cm}^{-1}$, Peak IV from the hydrogenbonded $-\mathrm{C}=\mathrm{O}$ in the amorphous region located at $1712-1713 \mathrm{~cm}^{-1}$ and Peak V from the hydrogenbonded $-\mathrm{C}=\mathrm{O}$ in the ordered domain located at $1697-1698 \mathrm{~cm}^{-1}$ [36]. The location and fraction of these three peaks in the WPU/ChW nanocomposites and WPU are also summarized in Table 1. Adding ChWs appeared to slightly decrease the fraction of the free $-\mathrm{C}=\mathrm{O}$ peak (Peak III), indicating that the hydrogen bonding associated with $-\mathrm{C}=\mathrm{O}$ of hard-segments and $\mathrm{PCL}_{2000}$ soft-segments was improved. This was attributed to the newly formed hydrogen bonds between the $-\mathrm{C}=\mathrm{O}$ of the WPU component and the $-\mathrm{OH}$ or $-\mathrm{NH}-$ on the $\mathrm{ChW}$ surface. Although hydrogen bonding associated $-\mathrm{C}=\mathrm{O}$ was improved as a whole, the effect of adding $\mathrm{ChW}$ on the region of hydrogen bonding in the nanocomposites was distinctly different. With an increase in the $\mathrm{ChW}$ loading level, the increasing fraction of Peak IV suggested that the improvement of hydrogen bonding occurred mainly in the amor- 

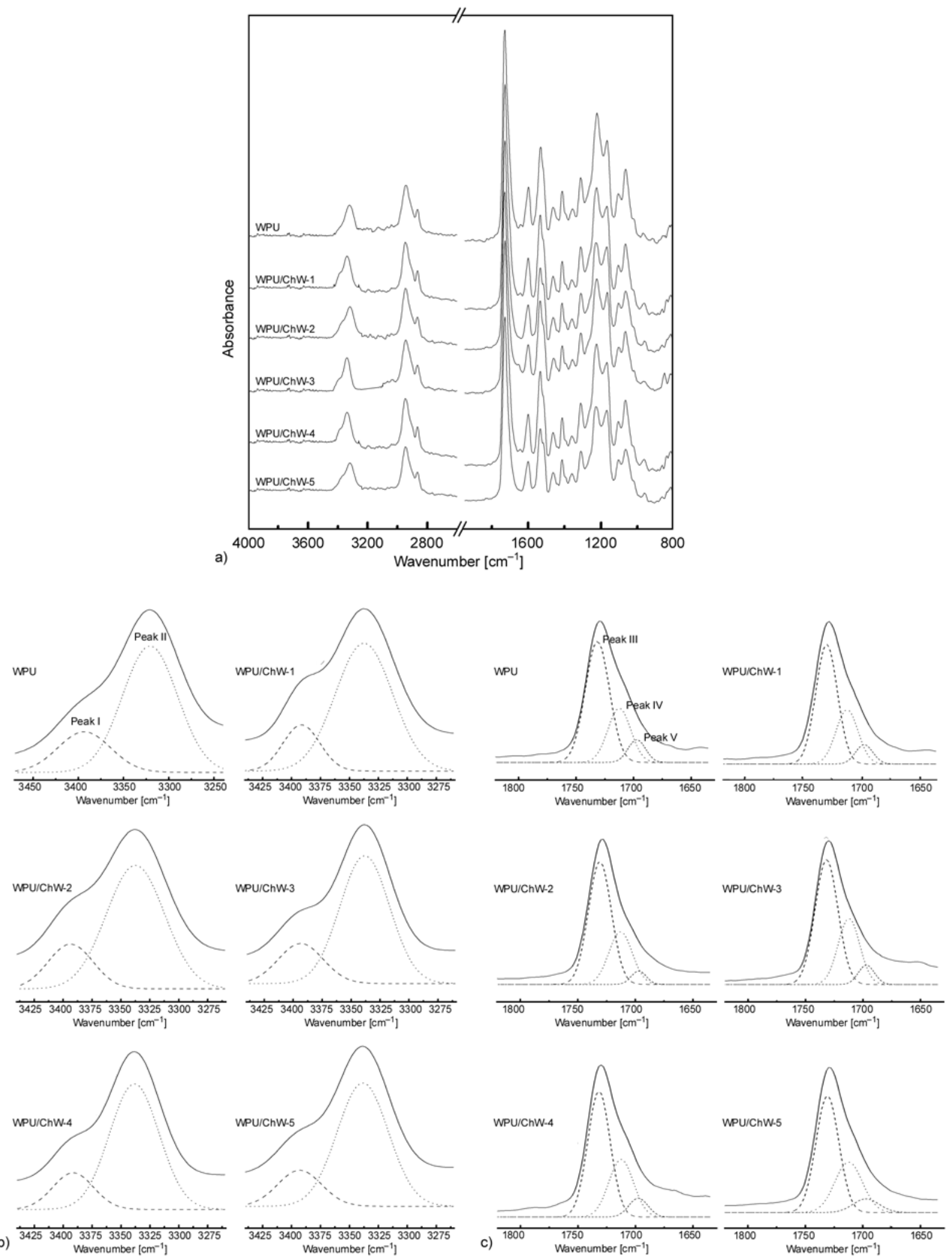

Figure 3. FTIR spectra of the WPU/ChW nanocomposite films and WPU film as reference ((a): full spectra; (b): the curvefitting for the $-\mathrm{NH}$ absorption of WPU/ChW nanocomposites as representive (- ${ }_{-}$experimental curve, $(---)$ free $-\mathrm{NH},(\cdots)$ hydrogen-bonded $-\mathrm{NH}$; (c): the curve-fitting for the $-\mathrm{C}=\mathrm{O}$ absorption of WPU/ChW nanocomposites as representive $(-)$ experimental curve, $(---)$ free $-\mathrm{C}=\mathrm{O},(\cdots)$ hydrogen-bonded $-\mathrm{C}=\mathrm{O}$ in amorphous region, (- - ) hydrogen-bonded $-\mathrm{C}=\mathrm{O}$ in ordered domain) 
Table 1. Location and Fraction of Curve-Fitting Peaks for the $-\mathrm{NH}$ and $-\mathrm{C}=\mathrm{O}$ Bands in the FTIR Spectra of WPU/ChW Nanocomposites and WPU (Peak I: Free -NH; Peak II: Hydrogen-Bonded -NH; Peak III: Free -C=O; Peak IV: Hydrogen-Bonded $-\mathrm{C}=\mathrm{O}$ in Amorphous Region; Peak V: Hydrogen-Bonded $-\mathrm{C}=\mathrm{O}$ in Ordered Domain).

\begin{tabular}{|c|c|c|c|c|c|c|c|c|c|c|}
\hline \multirow{3}{*}{ Sample code } & \multicolumn{4}{|c|}{-NH band } & \multicolumn{6}{|c|}{$-\mathrm{C}=\mathrm{O}$ band } \\
\hline & \multicolumn{2}{|c|}{ Peak I } & \multicolumn{2}{|c|}{ Peak II } & \multicolumn{2}{|c|}{ Peak III } & \multicolumn{2}{|c|}{ Peak IV } & \multicolumn{2}{|c|}{ Peak V } \\
\hline & $\begin{array}{c}\text { Location } \\
{\left[\mathrm{cm}^{-1}\right]}\end{array}$ & $\begin{array}{c}\text { Fraction } \\
{[\%]}\end{array}$ & $\begin{array}{c}\text { Location } \\
{\left[\mathrm{cm}^{-1}\right]}\end{array}$ & $\begin{array}{c}\text { Fraction } \\
{[\%]}\end{array}$ & $\begin{array}{c}\text { Location } \\
{\left[\mathrm{cm}^{-1}\right]}\end{array}$ & $\begin{array}{c}\text { Fraction } \\
{[\%]}\end{array}$ & $\begin{array}{c}\text { Location } \\
{\left[\mathrm{cm}^{-1}\right]}\end{array}$ & $\begin{array}{c}\text { Fraction } \\
{[\%]}\end{array}$ & $\begin{array}{c}\text { Location } \\
{\left[\mathrm{cm}^{-1}\right]}\end{array}$ & $\begin{array}{c}\text { Fraction } \\
{[\%]}\end{array}$ \\
\hline WPU & 3393.6 & 23.5 & 3320.8 & 76.5 & 1731.5 & 64.1 & 1712.4 & 27.2 & 1697.3 & 8.7 \\
\hline WPU/ChW-1 & 3393.1 & 19.6 & 3337.4 & 80.4 & 1730.2 & 62.8 & 1712.4 & 29.1 & 1697.5 & 8.1 \\
\hline WPU/ChW-2 & 3393.6 & 21.8 & 3337.4 & 78.2 & 1730.8 & 63.6 & 1712.9 & 29.8 & 1697.1 & 6.6 \\
\hline WPU/ChW-3 & 3393.6 & 21.1 & 3338.9 & 78.9 & 1731.7 & 62.1 & 1712.2 & 31.1 & 1697.1 & 6.8 \\
\hline WPU/ChW-4 & 3391.5 & 19.3 & 3338.9 & 80.7 & 1731.7 & 61.4 & 1712.4 & 30.8 & 1697.5 & 7.8 \\
\hline WPU/ChW-5 & 3393.1 & 18.9 & 3338.4 & 81.1 & 1730.8 & 60.4 & 1712.4 & 31.5 & 1697.3 & 8.1 \\
\hline
\end{tabular}

phous region, while the slight decrease in the fraction of Peak V proved the cleavage of hydrogen bonding in the ordered domain. Usually, hydrogen bonding in the ordered domain was constructed by hard-segments in the WPU matrix, which suggested that adding $\mathrm{ChW}$ drew down the original ordered alignment among hard-segments.

\subsection{Crystalline character of nanocomposites}

Figure 4 shows the XRD patterns of the WPU/ChW nanocomposites with various $\mathrm{ChW}$ loading levels, as well as neat WPU and ChWs. When the ChWs loading level was lower than $2 \mathrm{wt} \%$, the WPU/ChW nanocomposites inherited the amorphous nature of neat WPU, shown as a diffuse peak located at $20.06^{\circ}$ of $2 \theta$, in spite of the fact that $-\mathrm{C}=\mathrm{O}$-based

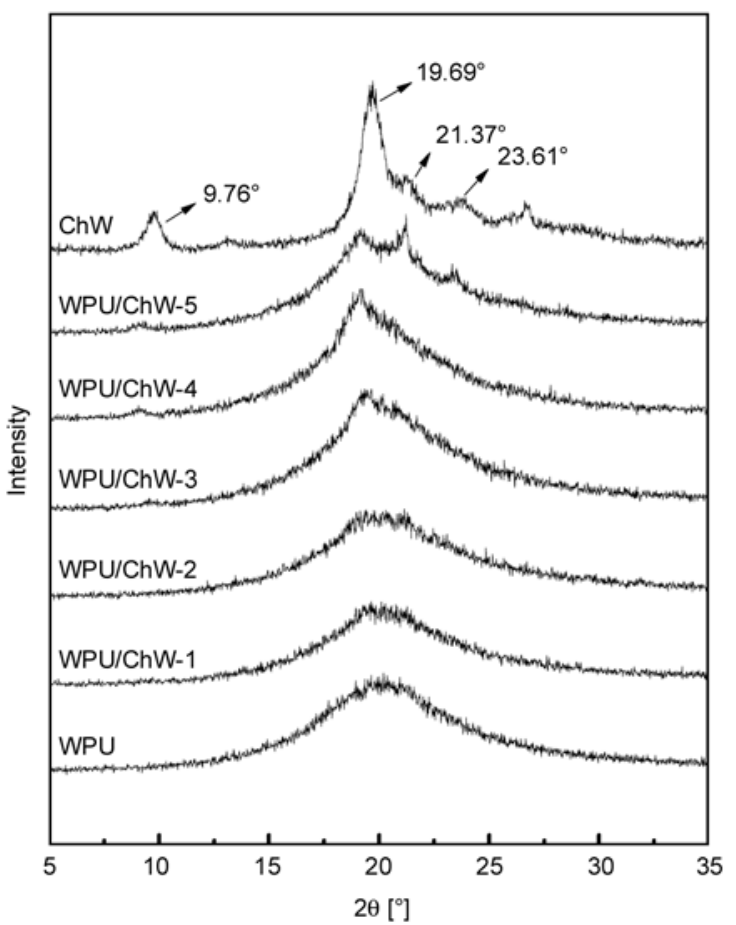

Figure 4. XRD patterns of WPU/ChW nanocomposites as well as WPU and freeze-dried ChW powder hydrogen bonds constructed a small scale ordered domain in the WPU matrix, as mentioned above. Although the ChWs had a semi-crystalline character, at low loading levels and with relatively uniform dispersion, the well-defined diffraction peaks were absent in the nanocomposites. When the $\mathrm{ChW}$ loading level increased to $3 \mathrm{wt} \%$, a weak diffraction peak appeared at $19.47^{\circ}$ of $2 \theta$, which corresponded to the strongest diffraction of semi-crystalline ChWs located at $19.69^{\circ}$ of $2 \theta$. When the ChW loading level increased to $4 \mathrm{wt} \%$, a diffraction peak appeared at $9.04^{\circ}$ of $2 \theta$. Furthermore, when the ChWs content reached $5 \mathrm{wt} \%$, two other obvious diffraction peaks appeared at 21.18 and $23.44^{\circ}$ of $2 \theta$, which corresponded to the diffraction of $\mathrm{ChW}$ located at 21.37 and $23.61^{\circ}$ of $2 \theta$ respectively. This proved that the ChWs existed in the nanocomposites and tended to self-aggregate with an increase in the ChW loading level.

\subsection{Thermal behaviour of nanocomposites}

DSC and DMA were used to further understand the interaction between the $\mathrm{ChW}$ nanofiller and the WPU matrix, as well as the structural changes to the WPU matrix and the distribution of ChWs, by observing the variances in the domain-scale glass transition and the molecular-level $\alpha$-relaxation assigned to the $\mathrm{PCL}_{2000}$ soft-segment, respectively. Table 2 summarizes the glass transition temperature at midpoint $\left(T_{\mathrm{g}, \mathrm{mid}}\right)$, the heat-capacity increment $\left(\Delta C_{\mathrm{p}}\right)$, the melting temperature $\left(T_{\mathrm{m}}\right)$ and the heat enthalpy $\left(\Delta H_{\mathrm{m}}\right)$ of the WPU/ChW nanocomposites and the neat WPU. In the WPU/ChW nanocomposites, the temperatures of glass transition $\left(T_{\mathrm{g}}\right)$ and $\alpha$ relaxation $\left(T_{\alpha}\right)$ of the $\mathrm{PCL}_{2000}$ soft-segment can be affected by ChWs in two opposite ways. First, the motion of the soft-segment may be suppressed by 
Table 2. DSC data for WPU/ChW nanocomposites and WPU reference

\begin{tabular}{|l|c|c|c|c|}
\hline \multicolumn{1}{|c|}{ Sample } & $\begin{array}{c}\mathbf{T}_{\mathbf{g}, \mathbf{m i d}} \\
{\left[{ }^{\circ} \mathbf{C}\right]}\end{array}$ & $\begin{array}{c}\Delta \mathbf{C}_{\mathbf{p}} \\
{[\mathbf{J} / \mathbf{g} \cdot \mathbf{K}]}\end{array}$ & $\begin{array}{c}\mathbf{T}_{\mathbf{m}, \mathbf{P C L}} \\
{\left[{ }^{\circ} \mathbf{C}\right]}\end{array}$ & $\begin{array}{c}\Delta \mathbf{H}_{\mathbf{m}, \mathbf{P C L}} \\
{[\mathbf{J} / \mathbf{g}]}\end{array}$ \\
\hline WPU & -47.5 & 0.19 & 45.2 & 2.34 \\
\hline WPU/ChW-1 & -46.7 & 0.24 & 45.2 & 2.75 \\
\hline WPU/ChW-2 & -45.9 & 0.24 & 46.4 & 4.15 \\
\hline WPU/ChW-3 & -44.3 & 0.28 & 47.2 & 4.44 \\
\hline WPU/ChW-4 & -45.4 & 0.32 & 48.9 & 6.24 \\
\hline WPU/ChW-5 & -45.9 & 0.28 & 47.4 & 6.59 \\
\hline
\end{tabular}

the steric hindrance of the rigid $\mathrm{ChW}$ nanophase and by hydrogen bonding onto the active ChW surface. This could result in a shift of $T_{\mathrm{g}}$ and $T_{\alpha}$ to a higher temperature. In the opposite way, incorporating ChWs may cleave the original interaction between the hard- and soft-segments and hence change the microphase structure in the WPU matrix. In other words, the soft-segment could escape from the binding of the hard-segment, leading to decreased $T_{\mathrm{g}}$ and $T_{\alpha}$. The $T_{\mathrm{g}, \text { mids }}$ of all the WPU/ChW nanocomposites were higher than that of neat WPU, suggesting that the restriction of ChWs to the mobility of soft-segments was dominant in spite of the inevitable cleavage of the original interaction between the hard- and soft-segments in the WPU matrix. When the ChW loading level was less than $2 \mathrm{wt} \%$, the rigid ChWs homogeneously dispersed into the WPU matrix, and then

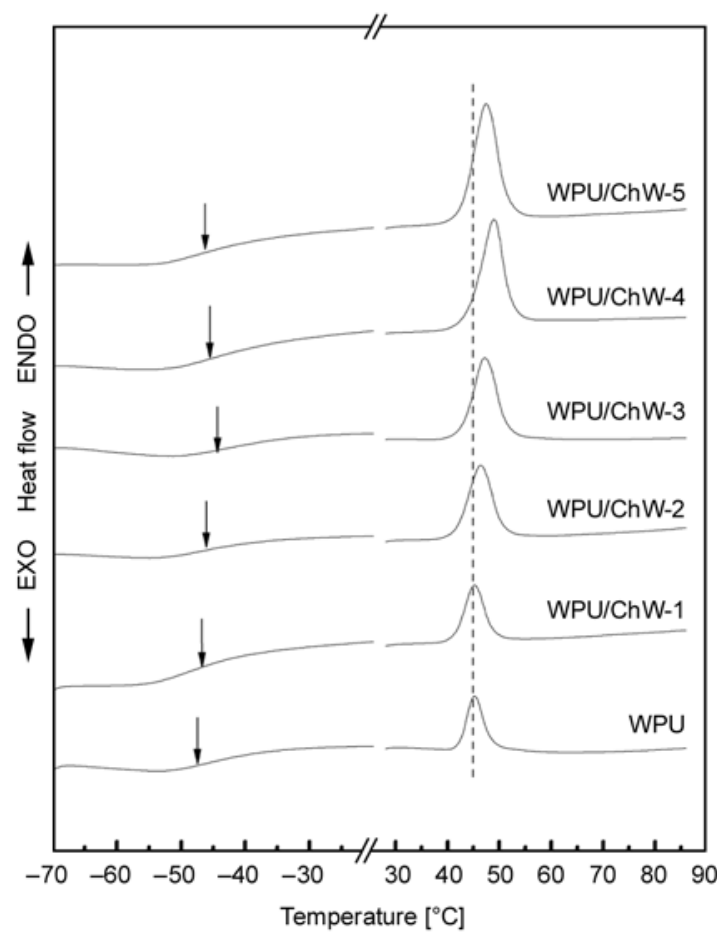

Figure 5. DSC thermograms of WPU/ChW nanocomposites and WPU as reference inhibited the motion of the soft-segment, mediated by the newly formed interaction with the WPU component. At this time, the $T_{\mathrm{g} \text {,mids }}$ increased with an increase in $\mathrm{ChW}$ loading level. When the $\mathrm{ChW}$ content reached $3 \mathrm{wt} \%, T_{\mathrm{g} \text {,mid }}$ of the nanocomposites showed the maximum value; however, increasing the $\mathrm{ChW}$ loading level caused the $T_{\mathrm{g} \text {,mids }}$ to gradually decrease because the increasing loading level of $\mathrm{ChW}$ induced self-aggregation of the ChWs and hence weakened the restriction to motion of the soft-segment. This was proven by the obvious diffraction peaks that corresponded to the semi-crystalline character of $\mathrm{ChW}$ in the XRD pattern. On the other hand, compared with the $\Delta H_{\mathrm{m}}$ value for the neat WPU of $2.34 \mathrm{~J} \cdot \mathrm{g}^{-1}$, all the WPU/ChW nanocomposites showed dramatically higher $\Delta H_{\mathrm{m}}$ values, suggesting that increasing the $\mathrm{ChW}$ loading level improved the crystallinity of the PCL component in the WPU matrix due to the nucleation effect of the ChW (Figure 5).

DMA is a powerful technique that reflects the mobility of the soft-segment through $\alpha$-relaxation at the molecular-level, for which the specific heat increment of the domain-scale glass transition as measured by DSC is generally ill-defined. Figure 6 shows the logarithm of the storage modulus $\left(\log E^{\prime}\right)$ and the tangent of the loss angle $(\tan \delta)$ as a function of temperature The $\alpha$-relaxation temperature at onset ( $\left.T_{\alpha \text { onset }}\right)$ and the corresponding storage modulus $\left(\log E^{\prime}\right), \alpha$-relaxation temperature of loss peak $\left(T_{\alpha \max }\right)$, and the tangent of loss angle $(\tan \delta)$ are summarized in Table 3. Obviously, the $T_{\alpha \text { max }}$ s of all the WPU/ChW nanocomposites were higher than that of neat WPU. Considering the improved hydrogen bonding associated with $-\mathrm{C}=\mathrm{O}$ in the amorphous region of the WPU matrix (seen in Table 1), the increase in $T_{\alpha \max } \mathrm{s}$ was attributed to the formation of interaction between the polar groups on the ChW surface and the WPU matrix. In this case, the suppression of ChWs to the mobility of soft-segments was proportional to the effective surface of ChWs. When the ChWs were homogeneously dispersed in the WPU matrix (the ChW loading level $<2 \mathrm{wt} \%$ ), the increasing interfacial area between the ChW nanofiller and the WPU matrix resulted in an increase in $T_{\alpha \max } \mathrm{S}$ and $T_{\alpha \text { onset }} \mathrm{S}$ with an increase of the $\mathrm{ChW}$ loading level. This is in good agreement with the DSC results. Thereafter, with a continuous increase in the loading level of $\mathrm{ChW}$, the ChWs 

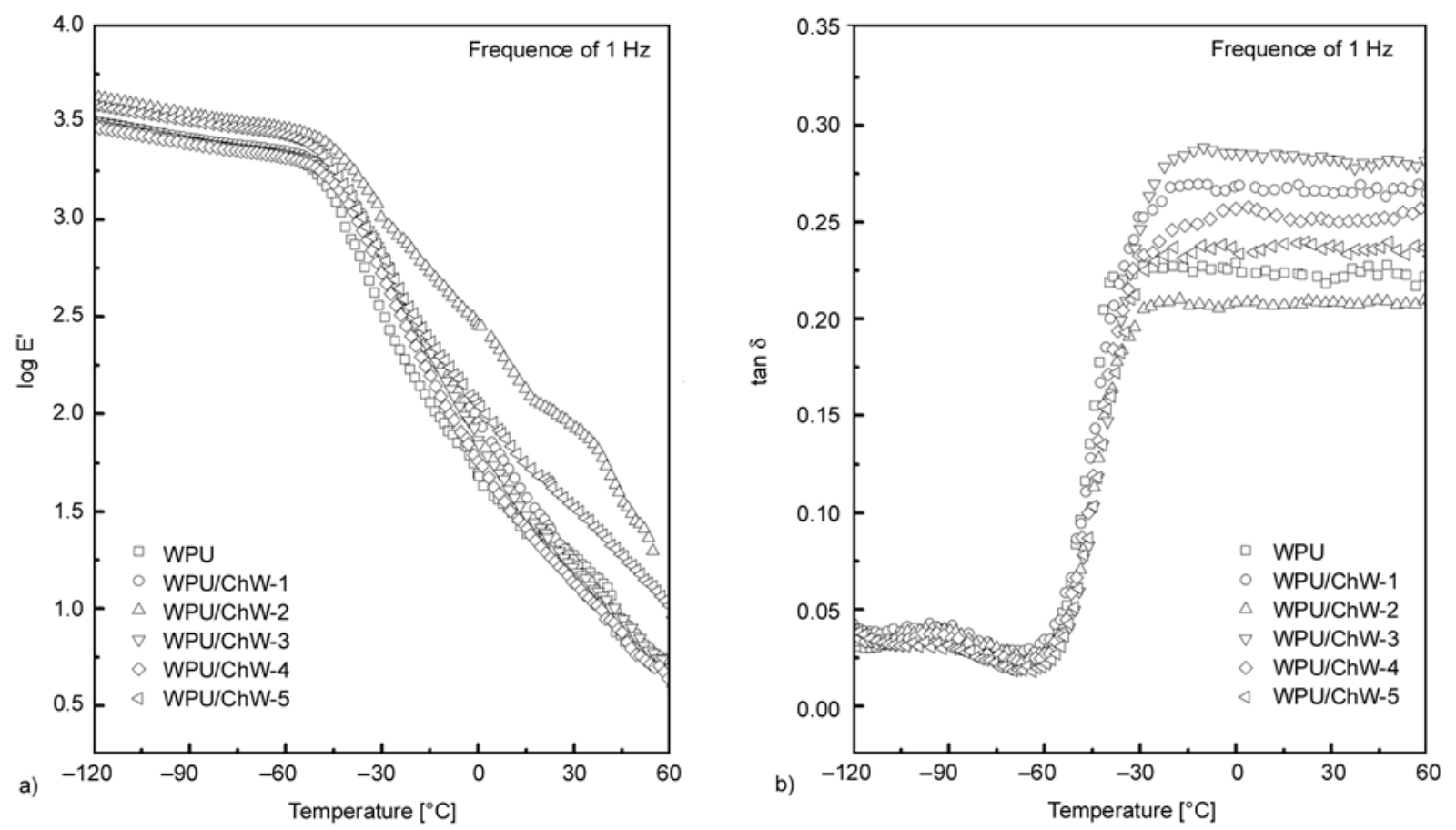

Figure 6. Logarithm of storage modulus $\left(\log E^{\prime}\right)$ and tangent of loss angle $(\tan \delta)$ vs. temperature measured at $1 \mathrm{~Hz}$ for WPU/ChW nanocomposites with various ChW loading levels, and WPU as reference

Table 3. DMA data for WPU/ChW nanocomposites and WPU reference

\begin{tabular}{|l|c|c|c|c|}
\hline \multicolumn{1}{|c|}{ Sample } & $\begin{array}{c}\mathbf{T}_{\boldsymbol{a} \text { onset }} \\
{\left[{ }^{\circ} \mathbf{C}\right]}\end{array}$ & $\begin{array}{c}\log \mathbf{E} \\
{[\mathbf{M P a}]}\end{array}$ & $\begin{array}{c}\mathbf{T}_{\boldsymbol{\alpha} \max } \\
{\left[{ }^{\circ} \mathbf{C}\right]}\end{array}$ & $\tan \boldsymbol{\delta}$ \\
\hline WPU & -49.5 & 3.16 & -30.4 & 0.22 \\
\hline WPU/ChW-1 & -48.1 & 3.20 & -30.0 & 0.26 \\
\hline WPU/ChW-2 & -45.7 & 3.37 & -29.8 & 0.20 \\
\hline WPU/ChW-3 & -43.3 & 3.18 & -24.5 & 0.28 \\
\hline WPU/ChW-4 & -44.6 & 3.21 & -28.9 & 0.24 \\
\hline WPU/ChW-5 & -45.5 & 3.26 & -29.5 & 0.21 \\
\hline
\end{tabular}

gradually self-aggregated, resulting in the decrease of $T_{\alpha \max }$ and $T_{\alpha \text { onset }}$ s for the WPU/ChW nanocomposites. In the WPU/ChW nanocomposites, the rigidity was mainly contributed by the ChWs nanophase as filler [37] and the ordered hard-segment domain of WPU matrix. Although the ordered hardsegment domain of WPU matrix partly cleaved after adding $\mathrm{ChW}$ (seen in the discussion on the hydrogen bonding associated with $-\mathrm{C}=\mathrm{O}$ in ordered domain), the $\log E^{\prime}$ of all the WPU/ChW nanocomposites were still higher than that of neat WPU due to the reinforcing function of rigid $\mathrm{ChW}$. This was in positive correlation with the Young's modulus $(E)$ of the nanocomposites.

\subsection{Fracture morphologies of nanocomposites}

Figure 7 shows the SEM images of fractured surfaces of the WPU/ChW nanocomposites and neat
WPU. When the ChW loading level was lower than $2 \mathrm{wt} \%$, the WPU/ChW nanocomposites (Figure $7 \mathrm{~b}$ and $7 \mathrm{c}$ ) showed a fluctuant fractured surface similar to that of neat WPU (Figure 7a). This was attributed to the fact that at a lower loading level ChW uniformly dispersed in the WPU matrix and had almost no effect on the original structure and fractured behaviour of the WPU matrix. However, with an increase in the ChW loading level, the fracture morphologies gradually became smooth surfaces with regular and compact thin stripes. This brittle-fracture characteristic was in agreement with the decrease in strength and elongation at break, and was attributed to breakage of the original structure of the WPU matrix after adding higher levels of ChWs. In addition, with an increase in the loading level of $\mathrm{ChW}$, the $\mathrm{ChW}$ nanophase in the WPU matrix could be observed, showing many white dots dispersed on the fracture surface. The SEM images seemed to verify the effects of increasing the $\mathrm{ChW}$ loading level on the increasing number and expanded size of the $\mathrm{ChW}$ nanophase in the nanocomposites.

\section{Conclusions}

New nanocomposite materials were prepared by casting and evaporating a mixture with waterborne 


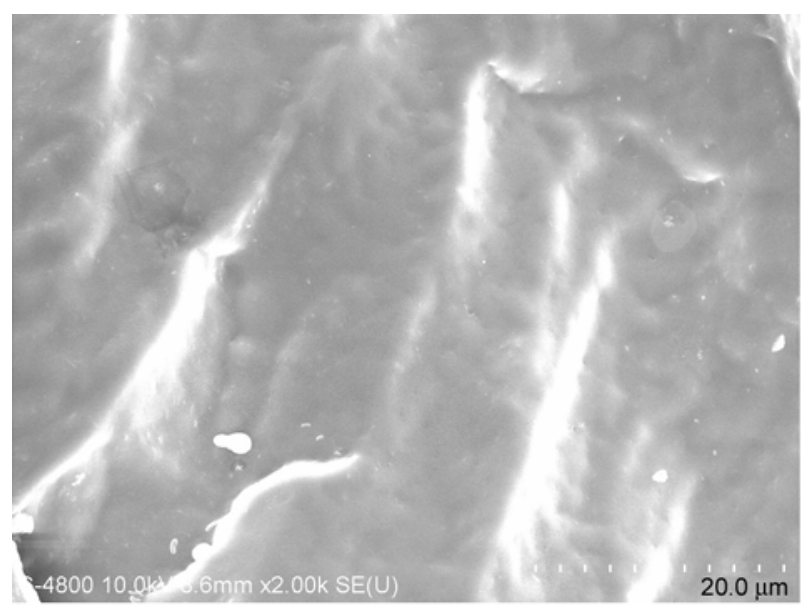

a)
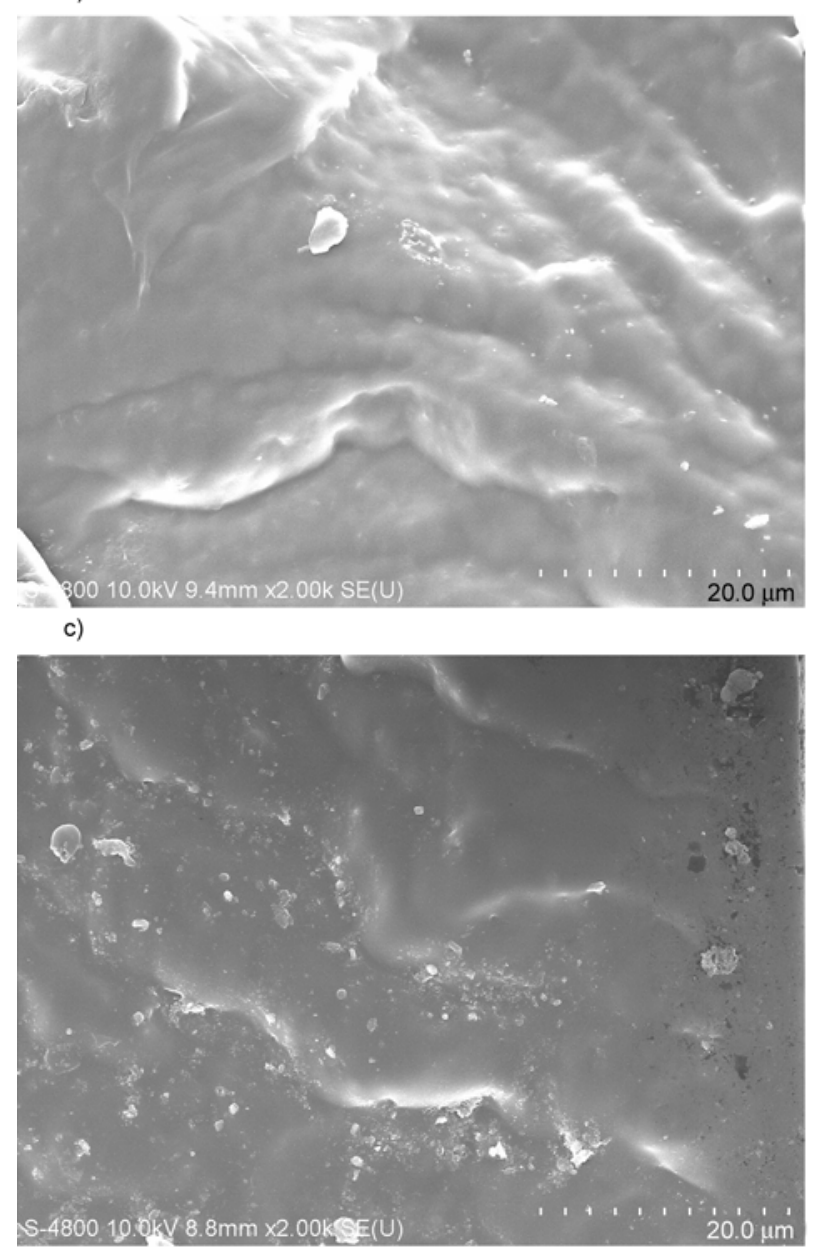

e)

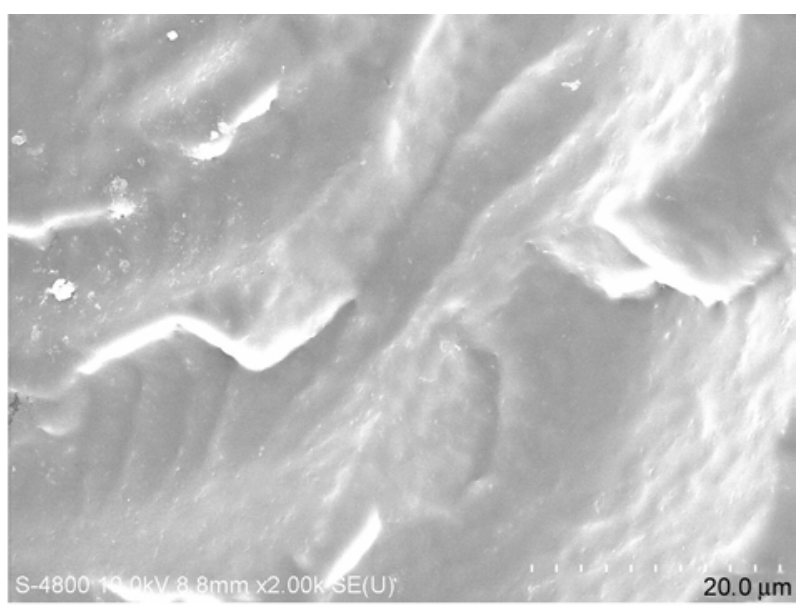

b)
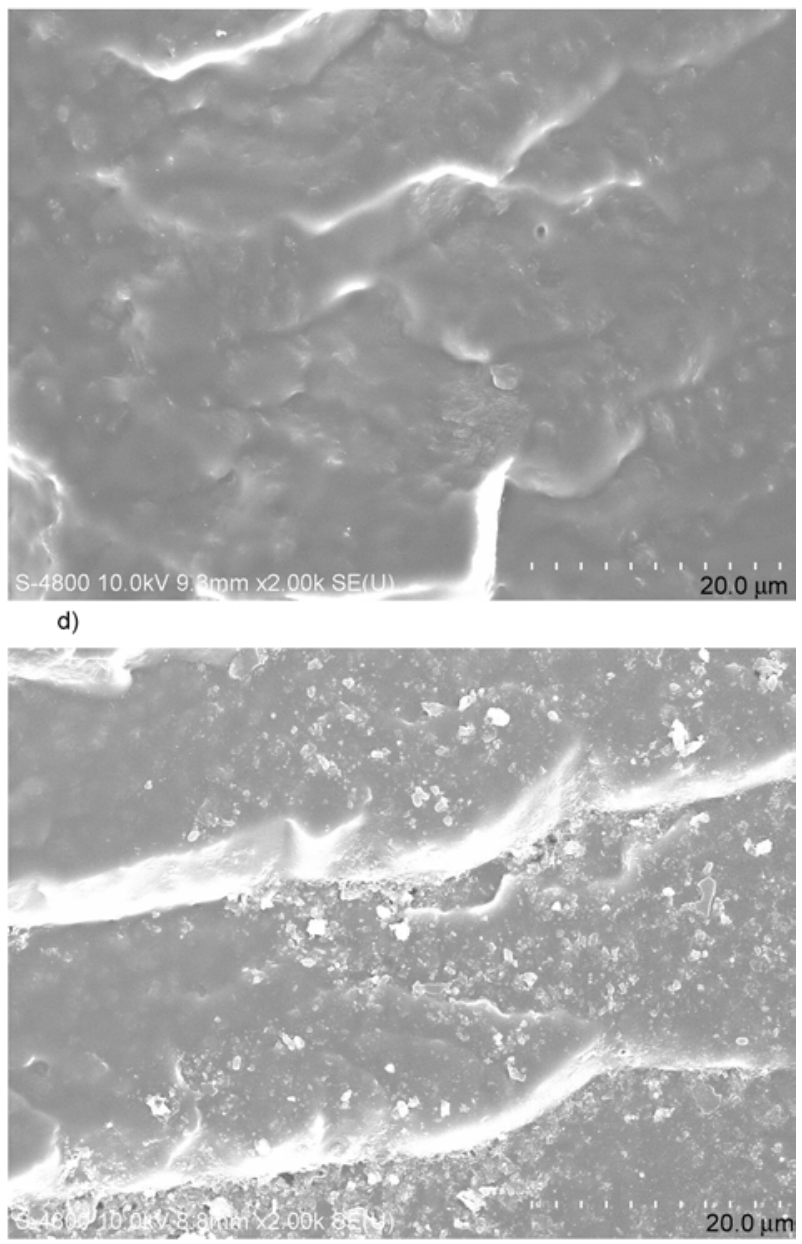

f)

Figure 7. SEM images of fractured surfaces of WPU/ChW nanocomposites with various $\mathrm{ChW}$ loading levels and WPU as reference. ((a): WPU; (b): WPU/ChW-1; (c): WPU/ChW-2; (d): WPU/ChW-3; (e): WPU/ChW-4; (f): WPU/ChW-5)

polyurethane (WPU) as matrix and chitin whiskers (ChW) as nanofiller. The strength and Young's modulus of the nanocomposites were simultaneously enhanced and maintained ca. 500\% elongation. Herein, the WPU/ChW-3 containing only $3 \mathrm{wt} \% \mathrm{ChWs}$ had the maximum tensile strength $(28.8 \mathrm{MPa})$ and enhanced Young's modulus
(6.5 MPa) that were ca. 1.8- and 2.2-fold over those of neat WPU, respectively. The WPU/ChW-5 containing $5 \mathrm{wt} \%$ ChWs had the highest Young's modulus $(9.6 \mathrm{MPa})$, which was enhanced by ca. $220 \%$. The prominent improvement of mechanical performance was attributed to the enduring stress of rigid $\mathrm{ChW}$ and stress transfer mediated by strong 
interactions between the ChW nanofiller and the WPU matrix. This work rendered a strategy for achieving high mechanical performance of waterborne polyurethane-based nanocomposites by a simple method, and the novel bionanocomposites developed could have great potential applications.

\section{Acknowledgements}

The research work was financially supported by the National Natural Science Foundation of China (50873080); Program of Energy Research and Development (PERD) of Canada; Agricultural Bio-products Innovation Program (ABIP) of Canada via the Pulse Research Network (PURENET); State Key Laboratory of Pulp and Paper Engineering (200906); and Fundamental Research Funds for the Central Universities (Self-Determined and Innovative Research Funds of WUT 2010-II-022).

\section{References}

[1] Mecking S.: Nature or petrochemistry? - Biologically degradable materials. Angewandte Chemie International Edition, 43, 1078-1085 (2004).

DOI: 10.1002 /anie.200301655

[2] Smith R.: Biodegradable polymers for industrial applications. CRC Press, London (2005).

[3] Wool R., Sun X. S.: Bio-based polymers and composites. Elsevier, London (2005).

[4] Azizi Samir M. A. S., Alloin F., Dufresne A.: Review of recent research into cellulosic whiskers, their properties and their application in nanocomposite field. Biomacromolecules, 6, 612-626 (2005).

DOI: $10.1021 / \mathrm{bm} 0493685$

[5] Paillet M., Dufresne A.: Chitin whisker reinforced thermoplastic nanocomposites. Macromolecules, 34, 6527-6530 (2001).

DOI: $10.1021 / \mathrm{ma} 002049 \mathrm{v}$

[6] Putaux J-L., Molina-Boisseau S., Momaur T., Dufresne A.: Platelet nanocrystals resulting from the disruption of waxy maize starch granules by acid hydrolysis. Biomacromolecules, 4, 1198-1202 (2003).

DOI: $10.1021 / \mathrm{bm} 0340422$

[7] Angellier H., Choisnard L., Molina-Boisseau S., Ozil P., Dufresne A.: Optimization of the preparation of aqueous suspensions of waxy maize starch nanocrystals using a response surface methodology. Biomacromolecules, 5, 1545-1551 (2004).

DOI: $10.1021 / \mathrm{bm} 049914 \mathrm{u}$

[8] Angellier H., Molina-Boisseau S., Dole P., Dufresne A.: Thermoplastic starch- waxy maize starch nanocrystals nanocomposites. Biomacromolecules, 7, 531-539 (2006).

DOI: $10.1021 / \mathrm{bm} 050797 \mathrm{~s}$
[9] Angellier H., Molina-Boisseau S., Dufresne A.: Mechanical properties of waxy maize starch nanocrystal reinforced natural rubber. Macromolecules, 38, 9161-9170 (2005).

DOI: $10.1021 / \mathrm{ma} 0512399$

[10] Yuan H., Nishiyama Y., Wada M., Kuga S.: Surface acylation of cellulose whiskers by drying aqueous emulsion. Biomacromolecules, 7, 696-700 (2006). DOI: $10.1021 / \mathrm{bm} 050828 \mathrm{j}$

[11] Angellier H., Molina-Boisseau S., Belgacem M. N., Dufresne A.: Surface chemical modification of waxy maize starch nanocrystals. Langmuir, 21, 2425-2433 (2005).

DOI: $10.1021 / \mathrm{la} 047530 \mathrm{j}$

[12] Thielemans W., Belgacem M. N., Dufresne A.: Starch nanocrystals with large chain surface modifications. Langmuir, 22, 4804-4810 (2006). DOI: $10.1021 / 1 \mathrm{a} 053394 \mathrm{~m}$

[13] Labet M., Thielemans W., Dufresne A.: Polymer grafting onto starch nanocrystals. Biomacromolecules, 8, 2916-2927 (2007). DOI: $10.1021 / \mathrm{bm} 700468 \mathrm{f}$

[14] Rinaudo M.: Chitin and chitosan: Properties and applications. Progress in Polymer Science, 31, 603-632 (2006).

DOI: 10.1016/j.progpolymsci.2006.06.001

[15] Martina M., Hutmacher D. W.: Biodegradable polymers applied in tissue engineering research: A review. Polymer International, 56, 145-157 (2007).

DOI: $10.1002 /$ pi.2108

[16] Senda T., He Y., Inoue Y.: Biodegradable blends of poly( $\varepsilon$-caprolactone) with $\alpha$-chitin and chitosan: Specific interactions, thermal properties and crystallization behavior. Polymer International, 51, 33-39 (2002). DOI: $10.1002 /$ pi.793

[17] He Y., Inoue Y.: Novel FTIR method for determining the crystallinity of poly( $\varepsilon$-caprolactone). Polymer International, 49, 623-626 (2000).

DOI: $10.1002 / 1097-0126(200006) 49: 6<623:: A I D-$ PI435>3.0.CO;2-8

[18] Zeng M., Gao H. N., Wu Y. Q., Fan L. R., Li A. P.: Preparation and characterization of nanocomposite films from chitin whisker and waterborne poly(esterurethane) with or without ultra-sonification treatment. Journal of Macromolecular Science Part A: Pure and Applied Chemistry, 47, 867-876 (2010). DOI: $10.1080 / 10601325.2010 .492277$

[19] Nair K. G., Dufresne A.: Crab shell chitin whisker reinforced natural rubber nanocomposites. 2. Mechanical behavior. Biomacromolecules, 4, 666-674 (2003). DOI: $10.1021 / \mathrm{bm} 0201284$

[20] Lu Y. S., Weng L. H., Zhang L. N.: Morphology and properties of soy protein isolate thermoplastics reinforced with chitin whiskers. Biomacromolecules, 5, 1046-1051 (2004).

DOI: $10.1021 / \mathrm{bm} 034516 \mathrm{x}$ 
[21] Wicks Z. W., Wicks D. A., Rosthauser J. W.: Two package waterborne urethane systems. Progress in Organic Coatings, 44, 161-183 (2002).

DOI: $10.1016 / \mathrm{S} 0300-9440(02) 00002-4$

[22] Noble K-L.: Waterborne polyurethanes. Progress in Organic Coatings, 32, 131-136 (1997). DOI: 10.1016/S0300-9440(97)00071-4

[23] Lin Y., Hsieh F., Huff H. E.: Water-blown flexible polyurethane foam extended with biomass materials. Journal of Applied Polymer Science, 65, 695-703 (1997).

DOI: 10.1002/(SICI) 1097-4628(19970725)65:4<695:: AID-APP8>3.0.CO;2-F

[24] Coogan R. G.: Post-crosslinking of waterborne urethanes. Progress in Organic Coatings, 32, 51-63 (1997). DOI: 10.1016/S0300-9440(97)00010-6

[25] Kim B. K., Kim T. K., Jeong H. M.: Aqueous dispersion of polyurethane anionomers from H12MDI/IPDI, PCL, BD, and DMPA. Journal of Applied Polymer Science, 53, 371-378 (1994).

DOI: 10.1002/app.1994.070530315

[26] Duecoffre V., Diener W., Flosbach C., Schubert W.: Emulsifiers with high chemical resistance: A key to high performance waterborne coatings. Progress in Organic Coatings, 34, 200-205 (1997).

DOI: $10.1016 / \mathrm{S} 0300-9440(98) 00032-0$

[27] Brinkman E., Vandevoorde P.: Waterborne two-pack isocyanate-free systems for industrial coatings. Progress in Organic Coatings, 34, 21-25 (1997). DOI: 10.1016/S0300-9440(98)00030-7

[28] Wu Q. X., Zhang L. N.: Structure and properties of casting films blended with starch and waterborne polyurethane. Journal of Applied Polymer Science, 79, 2006-2013 (2001).

DOI: $10.1002 / 1097-4628(20010314) 79: 11<2006:$ AIDAPP1009>3.0.CO;2-F

[29] Wang N. G., Zhang L. N.: Preparation and characterization of soy protein plastics plasticized with waterborne polyurethane. Polymer International, 54, 233239 (2005).

DOI: $10.1002 /$ pi.1696
[30] Cui G., Xia W., Chen G., Wei M., Huang J.: Enhanced mechanical performances of waterborne polyurethane loaded with lignosulfonate and its supramolecular complexes. Journal of Applied Polymer Science, 106, 4257-4263 (2007).

DOI: $10.1002 / a p p .27077$

[31] Zeng M., Zhang L. N., Wang N. G., Zhu Z. C.: Miscibility and properties of blend membranes of waterborne polyurethane and carboxymethylchitin. Journal of Applied Polymer Science, 90, 1233-1241 (2003). DOI: 10.1002/app.12660

[32] Cao X., Dong H., Li C. M.: New nanocomposite materials reinforced with flax cellulose nanocrystals in waterborne polyurethane. Biomacromolecules, 8, 899904 (2007).

DOI: $10.1021 / \mathrm{bm} 0610368$

[33] Morin A., Dufresne A.: Nanocomposites of chitin whiskers from riftia tubes and poly(caprolactone). Macromolecules, 35, 2190-2199 (2002).

DOI: $10.1021 / \mathrm{ma} 011493 \mathrm{a}$

[34] Kim D. H., Fasulo P. D., Rodgers W. R., Paul D. R.: Effect of the ratio of maleated polypropylene to organoclay on the structure and properties of TPO-based nanocomposites. Part I: Morphology and mechanical properties. Polymer, 48, 5960-5978 (2007). DOI: $10.1016 /$ j.polymer.2007.08.010

[35] Chen G. J., Wei M., Chen J. H., Huang J., Dufresne A., Chang P. R.: Simultaneous reinforcing and toughening: New nanocomposites of waterborne polyurethane filled with low loading level of starch nanocrystals. Polymer, 49, 1860-1870 (2008).

DOI: $10.1016 /$ j.polymer.2008.02.020

[36] Huang J., Zhang L. N.: Effects of $\mathrm{NCO} / \mathrm{OH}$ molar ratio on structure and properties of graft-interpenetrating polymer networks from polyurethane and nitrolignin. Polymer, 43, 2287-2294 (2002). DOI: $10.1016 / \mathrm{S} 0032-3861(02) 00028-9$

[37] Cui L., Ma X., Paul D. R.: Morphology and properties of nanocomposites formed from ethylene-vinyl acetate copolymers and organoclays. Polymer, 48, 6325-6339 (2007).

DOI: $10.1016 /$ j.polymer.2007.08.040 